\title{
Genotyping and Molecular Characterization of Carbapenem-resistant Acinetobacter baumannii Strains Isolated from Intensive Care Unit Patients
}

\author{
Rania Abozahra ${ }^{1}$, Sarah M. Abdelhamid ${ }^{1}$, Amel G. Elsheredy ${ }^{2}$, Kawther E. Abdulwahab ${ }^{1}$, and Kholoud Baraka ${ }^{1}$ \\ ${ }^{1}$ Department of Microbiology and Immunology, Faculty of Pharmacy, Damanhour University, Damanhour, Egypt \\ ${ }^{2}$ Department of Microbiology, Medical Research Institute, Alexandria University, Alexandria, Egypt
}

Received: August 20, 2020 / Revised: March 16, 2021 / Accepted: March 16, 2021

\begin{abstract}
The emergence of multidrug-resistant Acinetobacter baumannii has partly increased treatment failure and patient mortality. Class D $\beta$-lactamases is an important mechanism of resistance to beta-lactam antibiotics in this species. This study aimed to investigate the relationship between the presence oxacillinase gene and genetic fingerprints of $A$. baumannii isolates from the intensive care unit of an Egyptian tertiary care hospital. One hundred and twenty $A$. baumannii clinical isolates were collected. Multiplex PCR was performed to detect genes encoding oxacillinases (OXA-23, $O X A-24, O X A-51, O X A-58$ and $O X A-143)$. Molecular typing of all collected isolates was performed using random amplified polymorphic DNA (RAPD)-PCR assay. Out of 120 examined isolates, 92,88 and $84 \%$ were resistant to ertapenem, imipenem and meropenem, respectively. The species-specific, commonly present $O X A-51$ gene was found in all isolates while $O X A-23$ showed a high prevalence of $88 \%$ of isolates. $O X A-24$ and $O X A-143$ genes were detected in $3 \%$ and $1 \%$ of isolates, respectively. No $O X A-58$ gene was detected. Five clusters consisting of 19 genotypes were detected using RAPDPCR. Genotype A was the most prevalent, it was observed in $62 \%$ of the isolates followed by genotype B (12\%). These results revealed that genotypes $A$ and $B$ are common in the hospital. Results also demonstrate that RAPD-PCR is a rapid and reliable method for studying the clonal similarity among A. baumannii isolated from different clinical specimens.
\end{abstract}

Keywords: Acinetobacter baumannii, carbapenem resistance, oxacillinase genes, genotyping

\section{Introduction}

Emergence and spread of multidrug-resistant (MDR) Acinetobacter baumannii within hospitals has become a global serious concern [1]. It has been noticed over the last decades pathogen that pathogens are responsible for many severe infections, especially in the intensive care unit (ICU) patients and burn wards [1, 2]. They can cause bacteremia, ventilator-associated pneumonia, meningitis, urinary tract, wounds and burn infections [3].

\section{* Corresponding author}

Tel: +002 01284458834, Fax: +002 0453334596

E-mail: rania_abozahra@yahoo.com
Although, most of $A$. baumannii isolates were sensitive to carbapenems, and imipenem therapy was once the "gold standard" for pneumonia due to $A$. baumannii $[1,4]$, the widespread use of antibiotics has rapidly developed the resistance to many antimicrobials, including fluoroquinolones, carbapenems and aminoglycosides [5].

Some mechanisms result in $\beta$-lactam resistance in $A$. baumannii, including: (i) alterations of porin-like proteins, which results in decreased permeability to antibiotics; (ii) the activity of efflux pumps, that decreases the intracellular concentration of antibiotics; and (iii) $\beta$ lactamases production [6]. Among the previously mentioned mechanisms, carbapenemases (carbapenem- 
hydrolyzing $\beta$-lactamases) belonging to the molecular class D OXA enzymes (oxacillinases) have globally emerged as the major mechanism responsible for resistance to carbapenems in A. baumannii [7].

They are categorized into six main subclasses, the species-specific, commonly present chromosomal carbapenemase gene to this species $O X A-51$ and the acquired OXA- 24, OXA-23, OXA-143, OXA-58 and OXA-235 $\beta$ lactamases [6, 8]. Rapid development of MDR strains makes it essential to understand the epidemiology of nosocomial $A$. baumannii infections in order to design effective strategies to control their spread [9, 10]. It is necessary to differentiate between the epidemic strain and the epidemiologically unrelated Acinetobacter [11].

This requires the assessment of isolates on the subspecies level by epidemiological typing methods like random amplification of polymorphic DNA-PCR (RAPD-PCR) technique that has a specific impact in the epidemiological tracing due to the nature of RAPD profiling that produces fingerprints as well as it can be used to detect polymorphisms in a variety of organisms [12].

In RAPD-PCR, random primer sequences can be used in organisms in which a specific genome sequence is unknown [13]. Random parts of the genome of the organism are amplified, which are expected to be identical amongst related species, and similar banding patterns are to be produced in gel electrophoresis [14].

In this study, we aimed to characterize A. baumannii nosocomial isolates obtained from Medical Microbiology lab from ICU patients in Alexandria, Egypt, in terms of antimicrobial resistance, prevalence of oxacillinase genes, clonal relationship and investigate any relationship between these factors that could probably have an impact on the treatment of carbapenem resistant $A$. baumannii infections.

\section{Materials and Methods}

\section{Bacterial isolates}

One hundred and twenty A. baumannii clinical isolates were collected from the Medical Microbiology lab at Alexandria Main University Hospital (El-Meri hospital). These isolates were obtained from 120 ICU patients from July 2018 to January 2019. They were collected from diffrent clinical specimens including blood, mini broncho-alveolar lavage (miniBAL), sputum, urinary tract infection (UTI), wound infections and endotracheal intubation (ETI).

\section{Bacterial culture and Identification of A. baumannii clini- cal isolates}

Isolates were cultured for $18-24 \mathrm{~h}$ at $37^{\circ} \mathrm{C}$ on MacConkey's agar plates (Himedia, India). Non- lactose fermenting colonies were further examined. All isolates were identified as Acinetobacter by standard biochemical methods [15] and were confirmed as A. baumannii by using VITEK 2 automated instrument ID System (bioMérieux, France). Strain identities were further confirmed by PCR amplification of $O X A-51$ gene which is unique species-specific and commonly present in $A$. baumannii species using primers as describe previously (Table 1) [13, 14].

Table 1. Primers used for detection of OXA genes in this study.

\begin{tabular}{|c|c|c|c|c|}
\hline Target gene & Primer & Sequence & $\begin{array}{l}\text { Expected amplicon } \\
\text { size (bp) }\end{array}$ & Reference \\
\hline \multirow[t]{2}{*}{$O X A-23$} & OXA-23 F & 5'-GATCGGATTGGAGAACCAGA-3' & \multirow{2}{*}{501} & \multirow{2}{*}{ [17], [56] } \\
\hline & OXA-23 R & 5'-ATTTCTGACCGCATTTCCAT-3' & & \\
\hline \multirow[t]{2}{*}{ OXA-24 } & OXA-24 F & 5'-GGTTAGTTGGCCCCCTTAAA-3' & \multirow{2}{*}{246} & \multirow{2}{*}{ [17], [56] } \\
\hline & OXA-24 R & 5'-AGTTGAGCGAAAAGGGGATT-3' & & \\
\hline \multirow[t]{2}{*}{$O X A-51$} & OXA-51 F & 5'-TAATGCTTTGATCGGCCTTG-3' & \multirow{2}{*}{353} & \multirow{2}{*}{ [17], [56] } \\
\hline & OXA-51 R & 5'-TGGATTGCACTTCATCTTGG-3' & & \\
\hline \multirow[t]{2}{*}{ OXA-58 } & OXA-58 F & 5'-AAGTATTGGGGCTTGTGCTG-3' & \multirow{2}{*}{599} & \multirow{2}{*}{ [17], [56] } \\
\hline & OXA-58 R & 5'-CCCCTCTGCGCTCTACATAC-3' & & \\
\hline \multirow[t]{2}{*}{ OXA-143 } & OXA-143 F & 5'-TGGCACTTTCAGCAGTTCCT-3' & \multirow{2}{*}{149} & \multirow{2}{*}[56]{} \\
\hline & OXA-143 R & 5'-TAATCTTGAGGGGGCCAACC-3' & & \\
\hline
\end{tabular}




\section{Antimicrobial susceptibility testing}

The susceptibility testing of $A$. baumannii isolates against different antibiotics was carried out by the disc diffusion method (Modified Kirby-Bauer method) according to the Clinical Laboratory Standards Institute (CLSI) guidelines 2019 [18]. The antibiotics used in this study were piperacillin/tazobactam (TZP, $110 \mu \mathrm{g}$ ), cefotaxime (CTX, $30 \mu \mathrm{g}$ ), cefoperazone (CFS, $30 \mu \mathrm{g}$ ) ceftriaxone (CTR, $30 \mu \mathrm{g}$ ), ceftazidime (CAZ, $30 \mu \mathrm{g}$ ), cefepime (CPM, $30 \mu \mathrm{g}$ ), ertapenem (ETP, $10 \mu \mathrm{g}$ ), meropenem (MRP, $10 \mu \mathrm{g}$ ), imipenem (IPM, $10 \mu \mathrm{g}$ ), tetracycline (TE, $30 \mu \mathrm{g}$ ), co-trimoxazole (Trimethoprim/ sulfamethoxazole) (COT, $25 \mu \mathrm{g}$ ), gentamycin (GEN, $10 \mu \mathrm{g})$, amikacin (AK, $30 \mu \mathrm{g}$ ) and ciprofloxacin (CIP, $5 \mu \mathrm{g})$. The diameters of the zones of inhibition were recorded and interpreted according to the CLSI guidelines 2019 [18].

Isolates were considered as MDR when they were found to be resistant to at least three classes of the above mentioned antimicrobial agents [19]. Antibiotic discs were all purchased from (Himedia) and stored in the refrigirator $\left(2-8^{\circ} \mathrm{C}\right)$.

\section{Genomic DNA extraction of bacterial isolates}

Genomic DNA from A. baumannii was extracted using the boiling method as described previously [20] with some modifications. Briefly, 4-5 fresh colonies of each isolate were picked from MacConkey's agar plates and suspended in $400 \mu \mathrm{l}$ of sterile distilled water in a sterile Eppendorf tube. The bacterial suspensions were then boiled at $95^{\circ} \mathrm{C}$ for $10 \mathrm{~min}$, left to cool for $5 \mathrm{~min}$ on ice then centrifuged for $5 \mathrm{~min}$ at 14,000 rpm. The supernatants were then collected and transferred to sterile Eppendorf tubes as templates for use in PCR and RAPD assays.

\section{PCR amplification of antibiotic resistance genes}

The presence of $A$. baumannii genes encoding oxacillinases (OXA-24, OXA-23, OXA-58, and $O X A-143)$ were assessed in all 120 isolates using primers as described previously (Table 1). Each PCR was performed in dupli- cate in a thermocycler (Veriti, Germany, catalog number 4375786).

The thermal cycling program was made according to Woodford et al. [16] with some modifications. All PCR assays used $O X A-51$ gene as the internal control. The primers were evaluated separately and then in a multiplex format. PCR was carried out in $25 \mu \mathrm{l}$ reaction volume containing $12.5 \mu \mathrm{l}$ MyTaq Hot start DNA polymerase (Bioline, UK), $5.5 \mu \mathrm{l}$ of the extracted DNA sample and $1 \mu \mathrm{l}(10 \mathrm{pmol})$ of each primer. In each set of experiments, a negative control was included which was prepared by replacing the DNA template with distilled water. $A$. baumannii reference strain ATCC 19606 was used as positive control for $O X A-51$ gene. The amplification conditions were as follows: initial denaturation at $95{ }^{\circ} \mathrm{C}$ for $2 \mathrm{~min}, 30$ cycles of denaturation at $95^{\circ} \mathrm{C}$ for $30 \mathrm{~s}$, annealing at $52^{\circ} \mathrm{C}$ for $15 \mathrm{~s}$ and extension at $72^{\circ} \mathrm{C}$ for $10 \mathrm{~s}$ and a final extension at $72^{\circ} \mathrm{C}$ for $7 \mathrm{~min}$ [16].

PCR products were separated on $1.5 \%$ agarose gels (Bioline) and observed using an image analysis system, high-performance UV trans-illuminator (Biometra, Germany).

\section{Generation of DNA fingerprints by RAPD-PCR}

All our 120 isolates were analyzed by RAPD-PCR genotyping using AP2, AP5 and AP6 primers (Table 2). RAPD was performed by the method described previously [21]. Amplification was made in a final volume of $10 \mu \mathrm{l}$ of the amplification mixture containing $5 \mu \mathrm{l} \mathrm{MyTaq}$ Hot start DNA polymerase (Bioline), $1 \mu \mathrm{l}$ of the extracted DNA sample, $3 \mu \mathrm{l}$ water and $1 \mu \mathrm{l}(10 \mathrm{pmol})$ of a single primer (Table 2 ) of arbitrary nucleotide sequence following manufacturer's instructions.

Amplifications were performed in a thermal cycler as described previously [21] with some modifications, using the following program: initial denaturation $95^{\circ} \mathrm{C}$ for $1 \mathrm{~min}, 40$ cycles of denaturation at $95^{\circ} \mathrm{C}$ for $15 \mathrm{~s}$, annealing at $30^{\circ} \mathrm{C}$ for $15 \mathrm{~s}$, extension at $72^{\circ} \mathrm{C}$ for $30 \mathrm{~s}$ followed by a final extension $72^{\circ} \mathrm{C}$ for $5 \mathrm{~min}$. The PCR products were resolved using 1.5\% agarose gel. A 100 bp DNA ladder

Table 2. RAPD primers used in this study.

\begin{tabular}{clcc}
\hline RAPD primer & & Description & Sequence \\
\hline AP2 & Single primer of arbitrary nucleotide sequence (decamer) & 5'-GTTTCGCTCC-3' $^{\prime}$ & [57], [54] \\
AP5 & Single primer of arbitrary nucleotide sequence (decamer) & 5'-AACGCGCAAC-3' $^{\prime}$ & [57], [12] \\
AP6 & Single primer of arbitrary nucleotide sequence (decamer) & 5'-CCCGTCAGCA-3' $^{\text {[57], [11] }}$ \\
\hline
\end{tabular}


H3 RTU (GeneDirex, USA) was used. RAPD profiles were used to measure genetic relationships among $A$. baumannii isolates. The images of the gel was captured, and the banding pattern was analyzed using BioNumerics software from Applied Maths (Applied Maths, SintMartens-Latem, Belgium).

Dendrogram generation and degrees of homology were determined by Dice comparisons, and clustering correlation coefficients were calculated by the UPGMA (unweighted pair group method with arithmetic averages). Clustering was performed at $95 \%$ similarity cutoff as shown in Fig. 3.

\section{Results}

\section{Prevalence of $\boldsymbol{A}$. baumannii among clinical specimens}

During the period of the study, 120 isolates were identified as $A$. baumannii by VITEK 2 Automated Instrument ID System and confirmed by PCR amplification of $O X A-51$, the species-specific commonly present gene. Among them 110 isolates were found to be carbapenemresistant and 10 were carbapenem sensitive. Sixty (50\%) of our isolates were recovered from sputum, 25 (21\%) isolates were from MiniBAL, 16 (13\%) from wounds, 13 (11\%) from blood, 3 (2.5\%) from UTI and 3 (2.5\%) from ETI.

\section{Antimicrobial susceptibility of $\boldsymbol{A}$. baumannii isolates}

Prevalence of carbapenem resistance pattern indicated that 92, 88 and $84 \%$ were resistant to ertapenem, imipenem and meropenem, respectively. The resistance

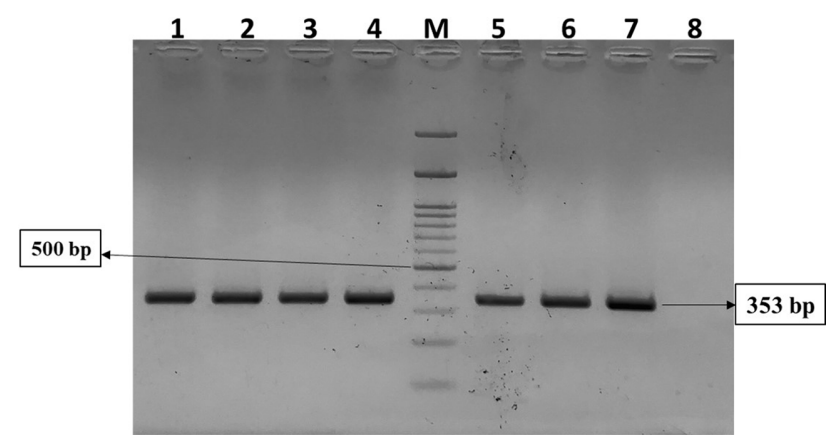

Fig. 1. PCR amplification of sputum isolates to confirm the presence of carbapenemase gene OXA-51 specific to $A$. baumannii on $\mathbf{1 . 5 \%}$ agarose gel. Lanes 1-6 show positive results at $353 \mathrm{bp}$ (for the isolates $1 \mathrm{sp}-6 \mathrm{sp}$ ), lane M shows $100 \mathrm{bp}$ DNA ladder, lane 7 shows positive result at $353 \mathrm{bp}$ for the positive control strain, lane 8 is the negative control (E. coli). to other $\beta$-lactam antibiotics was distributed as follows: piperacillin/tazobactam (92\%), Cefotaxime (92\%), Cefoperazone (92\%) Ceftriaxone (92\%), Cefepime (92\%), Ceftazidime (92\%), while resistance to other classes of antibiotics was distributed as follows: Amikacin (88\%), Gentamycin (85\%), Trimethoprim/sulfamethoxazole (68\%), Ciprofloxacin (90\%) and Tetracycline (54\%).

\section{Molecular characterization of Oxacillinase encoding genes}

PCR for oxacillinase-encoding genes revealed that $100 \%$ of $A$. baumannii isolates carried OXA-51 (Fig. 1) while multiplex PCR showed $88 \%$ carried $O X A-23,3 \%$ carried $O X A-24$ and 1\% carried OXA-143 (Table 3). However, $O X A-58$ was not detected in any of the tested isolates.

\section{RAPD Genotyping}

All 120 isolates were analyzed by RAPD-PCR genotyping using AP2, AP5 and AP6 primers. Primers AP2 and

Table 3. Prevalence of OXA resistant genes among different genotypes.

\begin{tabular}{|c|c|c|c|c|}
\hline \multirow{2}{*}{ OXA-genes } & \multicolumn{3}{|c|}{ Number of isolates carrying } & \multirow{2}{*}{$\begin{array}{c}\text { Total } \\
\text { number of } \\
\text { isolates }\end{array}$} \\
\hline & $\begin{array}{c}\text { OXA-23 } \\
(\%)\end{array}$ & $\begin{array}{c}\text { OXA-24 } \\
\text { (\%) }\end{array}$ & $\begin{array}{l}\text { OXA-143 } \\
(\%)\end{array}$ & \\
\hline$A$ & 73 (99\%) & - & - & 74 \\
\hline B & $12(86 \%)$ & $2(14 \%)$ & - & 14 \\
\hline C & $8(100 \%)$ & - & - & 8 \\
\hline D & $4(100 \%)$ & - & - & 4 \\
\hline $\mathrm{E}$ & $2(100 \%)$ & - & - & 2 \\
\hline $\mathrm{F}$ & $1(100 \%)$ & - & - & 1 \\
\hline G & $1(100 \%)$ & - & - & 1 \\
\hline $\mathrm{H}$ & $1(100 \%)$ & - & - & 1 \\
\hline I & $1(100 \%)$ & - & - & 1 \\
\hline$J$ & - & $1(100 \%)$ & $1(100 \%)$ & 1 \\
\hline K & - & $1(100 \%)$ & - & 1 \\
\hline $\mathrm{L}$ & $1(100 \%)$ & - & - & 1 \\
\hline M & $1(100 \%)$ & - & - & 1 \\
\hline $\mathrm{N}$ & - & - & - & 2 \\
\hline $\mathrm{O}$ & - & - & - & 3 \\
\hline$P$ & - & - & - & 2 \\
\hline $\mathrm{Q}$ & - & - & - & 1 \\
\hline $\mathrm{R}$ & - & - & - & 1 \\
\hline$S$ & - & - & - & 1 \\
\hline
\end{tabular}

$\%=$ number of positive OXA gene in this genotype/total number of isolates in this genotype 


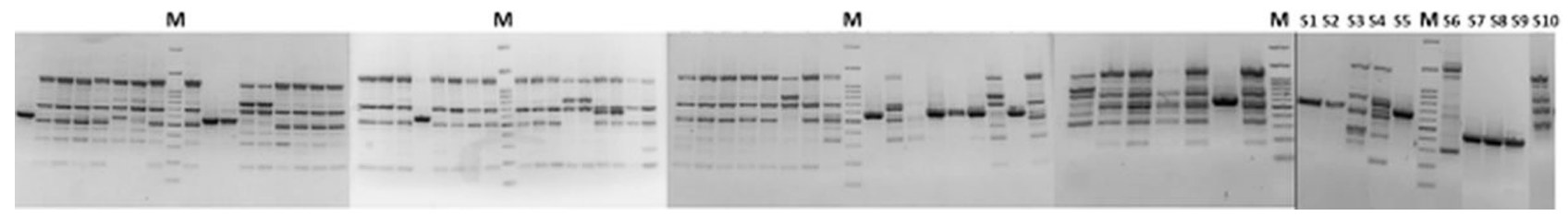

Fig. 2. RAPD-PCR fingerprinting of 58 of our carbapenem-resistant and 10 carbapenem-sensitive $A$. baumannii clinical isolates using AP5 oligonucleotide primer showing different genotypes. M: 100 bp DNA ladder, S1-S10 represent sensitive isolates, all unlabeled lanes represent the resistant isolates.

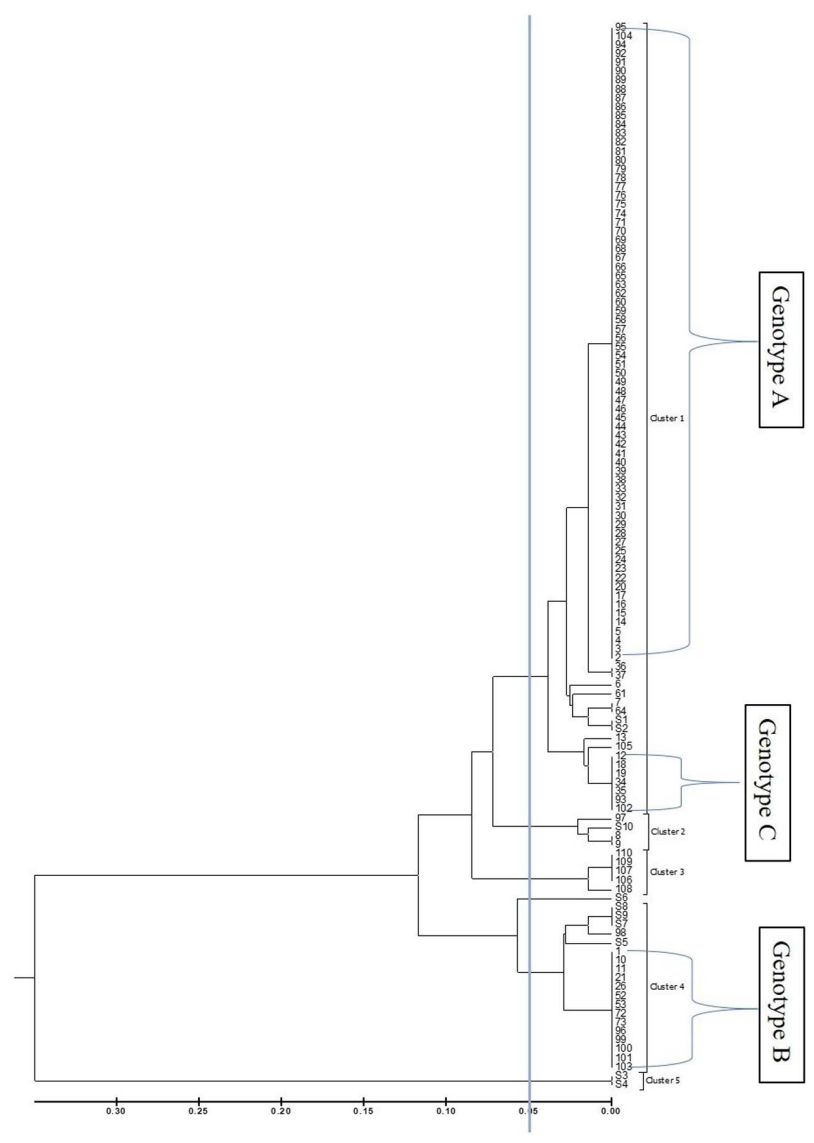

Fig. 3. Dendrogram of 120 A. baumannii isolates based on RAPD-PCR fingerprint. Clustering was performed based on unweighted pair group method with arithmetic mean. The blue vertical line shows $95 \%$ similarity cut-off.

AP6 gave reproducible patterns but often only a small number of bands were generated with many of the strains (data not presented). The decamer AP5 was chosen for this study because it produced the highest number of bands with our tested $A$. baumannii isolates in screening trials as shown in Fig. 2. The DNA banding patterns were analyzed by BioNumerics software version 7.6.3. (Applied Maths, Sint-Martens-Latem).
It was found that obtained fingerprints belong to 19 genomic types (Fig. 4), denoted from A to S. Genotypes A, B, C, D, E, F, G, H, I, J, K, L and M belong to carbapenem resistant $A$. baumannii which showed positive results to one or more of carbapenem resistance genes, while, genotypes $\mathrm{N}, \mathrm{O}, \mathrm{P}, \mathrm{Q}, \mathrm{R}$ and $\mathrm{S}$ belong to carbapenem sensitive $A$. baumannii which showed negative results to carbapenem resistance genes except for the species-specific $O X A-51$ gene.

$O X A-23$ is the most predominant among the resistant genotypes (A-M), while genotype (J) showed positive results for only $O X A-24$ and $O X A-143$. Genotypes B and $\mathrm{K}$ showed positive results for $O X A-23$ and $O X A-24$. Sensitive isolate genotypes (N-S) did not show any positive results for $O X A$ genes. It was concluded that genotype $\mathrm{A}$ and genotype $\mathrm{B}$ were present in all sample sources except for UTI and ETI isolates, respectively.

Five main clusters were obtained from the analysis of the dendrogram as shown in Fig. 3, where cluster 1 contained genotypes A, C, E, F, G, H, I and L, these 8 genotypes showed $95 \%$ similarity between them. Cluster 2 contained genotypes $\mathrm{J}$ and $\mathrm{S}$ and cluster 3 contained genotypes D and M. Cluster 4 contained genotypes B, K, $\mathrm{O}$ and $\mathrm{Q}$ all these clusters showed 95\% similarity between different genotypes. However, cluster 5 is considered an outgroup as there is no similarity with other clusters. As shown from Fig. 3 each genotype belongs only to one cluster. Some clonally related groups (A and B) were observed in most of the isolate sources which represent the dissemination of these clones in the hospitals (Fig. 5).

\section{Discussion}

A. baumannii has emerged as an important cause of healthcare-associated infections with high morbidity and mortality rates [1]. Previously, carbapenems were 


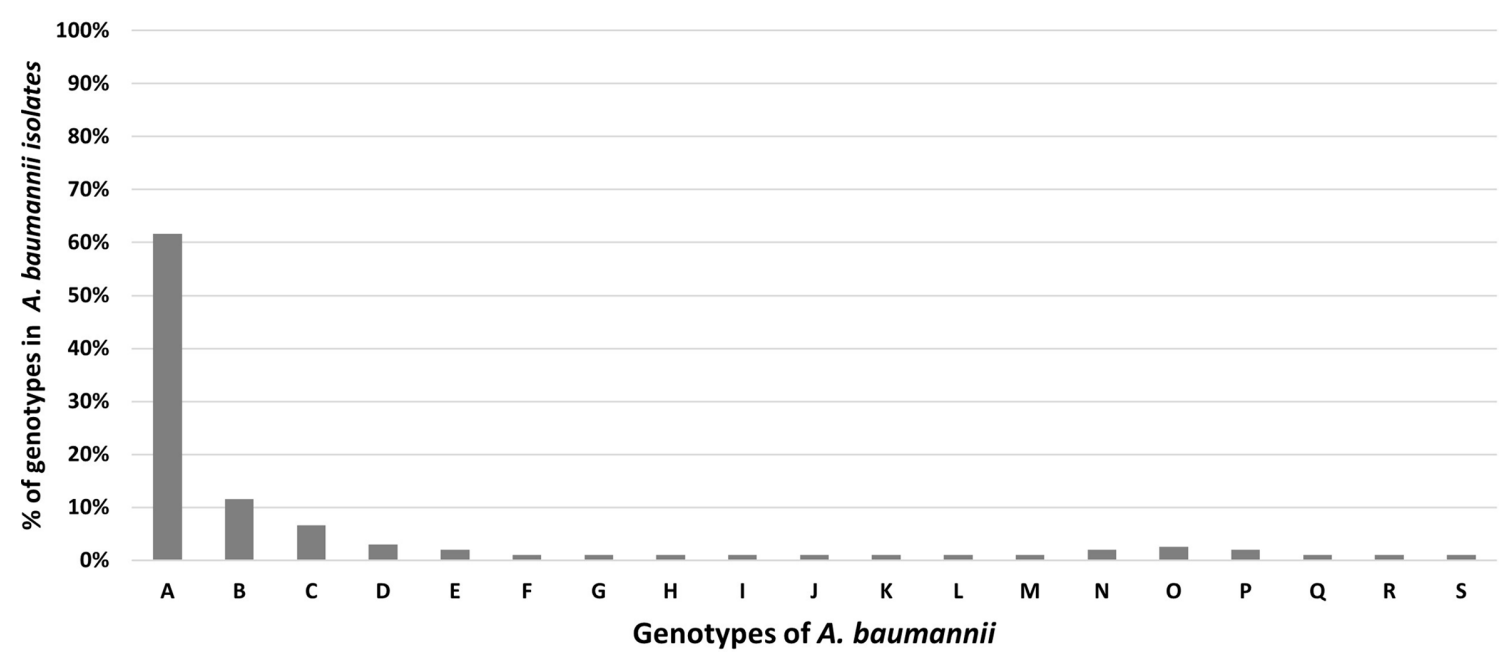

Fig. 4. Different Genotypes of A. baumannii and the percentage of isolates present in each genotype.

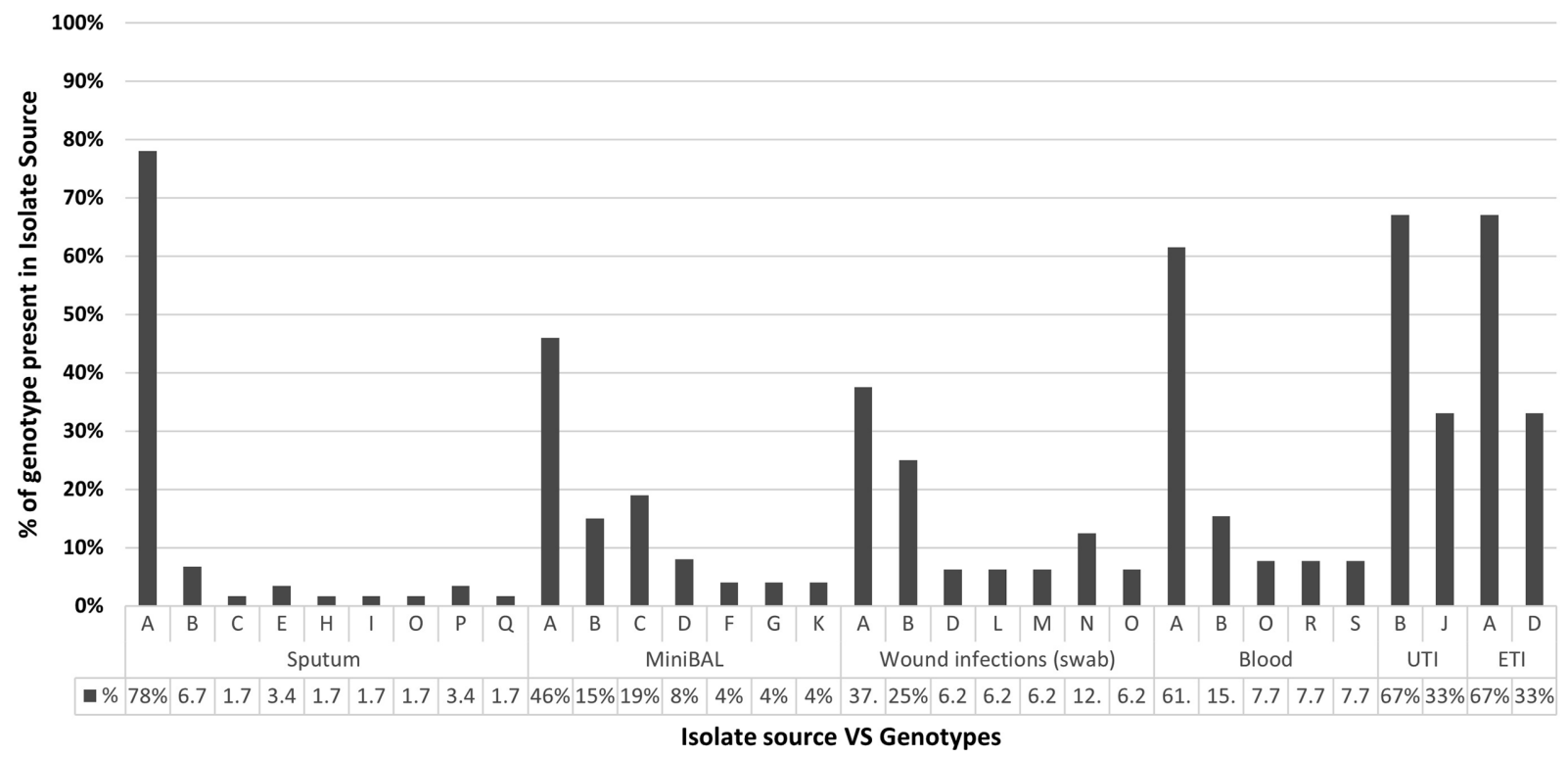

Fig. 5. The relation between the isolates source and different Genotypes A-S: represents the 19 different genotypes obtained in this study. *UTI: urinary tract infections, ETI: endotracheal intubation

the antibiotics of choice for treatment of MDR $A$. baumannii [22]. Nevertheless, carbapenem over-use and misuse for treatment of Acinetobacter infections became responsible for the occurrence of carbapenem resistant $A$. baumannii (CRAB) [23] which is considered a substantial health problem globally due to limited therapeutic options [6, 21]. During the period of the study, 120 isolates were identified as A. baumannii and identification was confirmed by the amplification of the species-specific $O X A-51$ gene. Half of our tested $A$. baumannii isolates were obtained from sputum samples (50\%) this is in agreement with a study made in Egypt [25], 21\% of the isolates were obtained from MiniBAL and $13 \%$ from wound which is in accordance to a study in Iran [26]. The rest of the isolates were obtained from blood (11\%), UTI (2.5\%) and ETI (2.5\%).

The resistance of our A. baumannii isolates to cephalosporins was in accordance to the findings of studies done in hospitals in Egypt [27], Iran [28], Bulgaria [29] and Nigeria [30] where the resistance was found to be 90 
$100 \%$ which could be due to the over-use of cephalosporins in these hospitals. The resistance of our isolates to amikacin (88\%) and gentamicin (85\%) was in agreement to the results of studies made in Bulgaria (90\%) [29] and Iran (81\%) [31] respectively. In contrast, few studies carried out in hospitals in Nepal and Malaysia showed that it was as low as $43.2-52.3 \%$ and $66.7 \%$ respectively, which could have resulted from the controlled use of aminoglycosides in such hospitals [14, 29]. Resistance to quinolone, like ciprofloxacin (90\%), was in accordance to a study from Egypt which showed a resistance of $90 \%$ [25]. After the development of resistance to fluoroquinolones, carbapenems are often the drug of choice for infections resulting from Multi-drug resistant A. baumannii but unfortunately, carbapenem-resistant isolates are continuously increasing [11]. In the present study, the resistance to ertapenem, imipenem and meropenem were 92,88 and $84 \%$ "respectively" which were in accordance to the findings from the studies in Egypt [22, 30] and other parts of the world [26, 31].

Carbapenemase production is known to be one of the main resistance mechanisms of $A$. baumannii to carbapenems [35]. Oxacillinases (Class D $\beta$-lactamases) are the most prevalent class in A. baumannii [36], and the genes encoding oxacillinases include $O X A-51$ which is speciesspecific and is present commonly in all $A$. baumannii and the acquired $O X A-24, O X A-23, O X A-58$, and $O X A$ $143[6,8]$. Worldwide spreading of MDR A. baumannii harboring OXA-type carbapenemase has progressively been reported [25].

$O X A-51$ is widely prevailing and is chromosomally located [37]. Many studies have pointed out that the identification of the $O X A-51$ gene is a rapid and reliable method for identifying $A$. baumannii $[34,35]$. This is in agreement with our study which showed that all our isolates harbored the $O X A-51$ gene. $O X A-23$ is the most frequent type of carbapenemase found among CRAB [30, 36, 37]. OXA-23-type carbapenemase-producing $A$. baumannii are becoming progressively widespread, with reports emerging from USA, Europe, Asia, Africa, Australia and the Middle East [1]. Outbreaks in Egypt [25], Spain [41], Italy [42], and the United States [43] were also described. In this study, most of our isolates were carbapenem resistant and the most prevalent gene in A. baumannii was found to be $O X A-23$, with a prevalence rate of $88 \%$, which is similar to studies in Iran [44] and Kuwait [45]. However, Fouad et al. detected OXA-23 in all their collected $A$. baumannii isolates [33]. In contrast, a study which was carried out in Egypt and Saudi Arabia showed a decreased percentage for $O X A-23$ gene carriage, $69 \%$ of their A. baumannii isolates [46]. Such variation in prevalence data suggests that various strains circulating in these countries have different frequencies in harboring the $O X A-23$ gene.

In this study, $3 \%$ of the isolates carried $O X A-24$ which is in agreement to a study reported by Zowawi et al. [47]. In other studies conducted in Egypt, Iran and Palestine $O X A-24$ was present in $7.5,11.8$ and $14.5 \%$ of the isolates respectively [37, 48, 49]. In contrast, other studies carried out in China and Egypt reported that OXA-24 was not detected in any of the tested isolates [50, 51]. However, $1 \%$ of our isolates carried OXA-143 which is similar to that detected by $\mathrm{Al}$ Atrouni et al. [52]. In contrast, a study in Iran reported high prevalence of $O X A$ 143 gene carriage (56\%) in tested isolates [48]. On the other hand, absence of $O X A-143$ gene carriage was reported by Handal et al. [49]. To our knowledge this is the first report of the presence of $O X A-143$ in Alexandria hospitals sounding an alarm to start to design strategies against the dissemination of MDR $A$. baumannii all over the country.

Moving on to $O X A-58$, which was not detected in any of the tested isolates, our results were similar to studies reported in Kuwait [45], Gulf Cooperation Council States [47] and China [50].

In conclusion, $O X A-24, O X A-143$ and $O X A-58$ were present at low prevalence in this study suggesting that their role in conferring resistance to carbapenems among the tested isolates may be limited, in contrast to the increase in carbapenem resistance amongst $A$. baumannii isolates. Therefore, to determine the genetic diversity of $A$. baumannii isolates and explore its putative relationship with antibiotic resistance, RAPD-PCR is used to generate DNA fingerprints to distinguish between bacterial strains and has been frequently applied in molecular diagnosis in hospital infections as it has several advantages including high sensitivity, specificity and ease of performance [50,51].

On the basis of RAPD profiles in agarose gels in this study, the number of bands ranged from 1 to 5 ranging in size from 300-1500 bp (Fig. 2). It indicated a high genetic diversity (A-S) among A. baumannii isolates 
from Alexandria, Egypt. Some clonally related groups (A and $\mathrm{B}$ ) were observed in most of the isolate sources which represent the dissemination of these clones in the hospitals (Fig. 5). Therefore, spreading of these two genotypes into different isolate sources also confirms their widespread distribution.

Moreover, in a study conducted in China in which 47 sensitive strains and $80 \mathrm{MDR}$ strains were isolated, seventeen genotypes $(\mathrm{A}-\mathrm{Q})$ were obtained. Genotype $\mathrm{E}$ was the predominant type in MDR strains (46/80) mainly derived from the ICU. The carriage rates of resistant genes revealed that $O X A-23$ carrying strains showed a resistance rate of $82.5 \%(66 / 80)$ and to a lower extent the presence of $O X A-24$ gene [54].

Similar to our study, RAPD genotyping carried out in Iran and Bulgaria revealed that most of the isolates belong to two main clones [28, 29]. Despite all these studies, more comprehensive studies are needed to prevent hospital-acquired infections via determining the sources of bacteria.

Having several clusters with predominance of $O X A-23$ gene may suggest its horizontal transmission between the different isolates, as $O X A-23$ has been proven to be plasmid-encoded [55], thus propagating antibiotic resistance and further complicating treatment options.

RAPD-PCR provided us with a powerful tool for identifying and epidemiologically typing our strains. Studying the epidemiology of MDR A. baumannii strains is crucial to avoid the clonal dissemination of antibioticresistant strains. Determining the genetic relation between clinical isolates shows the importance of surveillance programs, antimicrobial stewardship and strict infection control procedures that would affect health policy and decision-making. These are necessary to decrease the worldwide spread of carbapenem resistant $A$. baumannii.

\section{Conflict of Interest}

The authors have no financial conflicts of interest to declare.

\section{References}

1. Peleg AY, Seifert H, Paterson DL. 2008. Acinetobacter baumannii: Emergence of a successful pathogen. Clin. Microbiol. Rev. 21: 538582.

2. Kempf M, Rolain J. 2012. Emergence of resistance to carbapenems in Acinetobacter baumannii in Europe : Clinical impact and thera- peutic options. Int. J. Antimicrob. Agents 39: 105-114.

3. Maragakis LL, Perl TM. 2008. Acinetobacter baumannii: Epidemiology, antimicrobial resistance, and treatment options. Clin. Infect. Dis. 46: 1254-1263.

4. Shete VB, Ghadage DP, Muley VA, Bhore AV. 2010. Multi-drug resistant Acinetobacter ventilator-associated pneumonia. Lung India 27: 217-220.

5. Manageiro V, Jones-Dias D, Ferreira E, Louro D. 2012. Genetic diversity and clonal evolution of carbapenem-resistant Acinetobacter baumannii isolates from Portugal and the dissemination of ST118. Int. J. Antimicrob. Agents 40: 398-403.

6. Perez F, Hujer AM, Hujer KM, Decker BK, Rather PN, Bonomo RA. 2007. Global challenge of multidrug-resistant Acinetobacter baumanni. Antimicrob. Agents Chemother. 51: 3471-3484.

7. Lee H, Chen C, Wang S, Su L, Chen S, Liu S, et al. 2011. Imipenem heteroresistance induced by imipenem in multidrug-resistant Acinetobacter baumannii : mechanism and clinical implications. Int. J. Antimicrob. Agents 37: 302-308.

8. Turton JF, Woodford N, Glover J, Yarde S. 2006. Identification of Acinetobacter baumannii by detection of the blaOXA-51-like carbapenemase gene intrinsic to this species. J. Clin. Microbiol. 44: 2974-2976.

9. Lob SH, Hoban DJ, Sahm DF, Badal RE. 2016. Regional differences and trends in antimicrobial susceptibility of Acinetobacter baumannii. Int. J. Antimicrob. Agents 47: 317-323.

10. Morfin-otero R, Dowzicky MJ. 2012. Changes in MIC within a global collection of Acinetobacter baumannii collected as part of the tigecycline evaluation and surveillance trial, 2004 to 2009. Clin. Ther. 34: 101-112.

11. Rynga D, Shariff M, Deb M. 2015. Phenotypic and molecular characterization of clinical isolates of Acinetobacter baumannii isolated from Delhi, India. Ann. Clin. Microbiol. Antimicrob. 14: 40.

12. Nasr RA, Attalah MF. 2012. Molecular epidemiology of nosocomial Acinetobacter baumannii isolates. Nat. Sci. 10: 76-82.

13. Bart A, Schuurman IGA, Achtman M, Caugant DA, Dankert J, Ende A. 1998. Randomly amplified polymorphic DNA genotyping of serogroup a meningococci yields results similar to those obtained by multilocus enzyme electrophoresis and reveals new genotypes. J. Clin. Microbiol. 36: 1746-1749.

14. Leal NC, Sobreira M, Leal-Balbino TC, Almeida AMP De, de Silva MJ, Mello DM, et al. 2004. Evaluation of a RAPD-based typing scheme in a molecular epidemiology study of Vibrio cholerae 01, Brazil. J. Appl. Microbiol. 96: 447-454.

15. Constantiniu S, Romaniuc A, lancu LS, Filimon R. 2004. Cultural and biochemical characteristics of Acinetobacter spp. strains isolated from hospital units. J. Prev. Med. 12: 35-42.

16. Woodford N, Ellington MJ, Coelho JM, Turton JF, Ward ME, Brown $\mathrm{S}$, et al. 2006. Multiplex PCR for genes encoding prevalent OXA carbapenemases in Acinetobacter spp. Int. J. Antimicrob. Agents 27: 351-353.

17. Joshi PR, Acharya M, Kakshapati T, Leungtongkam U, Thummeepak R, Sitthisak S. 2017. Co-existence of blaOXA-23and blaNDM-1genes of Acinetobacter baumannii isolated from Nepal: 
Antimicrobial resistance and clinical significance. Antimicrob. Resist. Infect. Control 6: 21.

18. Clinical Laboratory Standards Institute(CLSI). 2019. Performance standards for antimicrobial susceptibility testing. Clin. Lab Stand Inst. 29th ed., pp. 1-319.

19. Manchanda V, Sinha S, Singh N. 2010. Multidrug resistant Acinetobacter. J. Glob Infect. Dis. 2: 291-304.

20. Graser Y, Klare I, Halle E, Gantenberg R, Buchholz P, Jacobi HD, et al. 1993. Epidemiological study of an Acinetobacter baumannii outbreak by using polymerase chain reaction fingerprinting. $J$. Clin. Microbiol. 31: 2417-2420.

21. Karthika RU, Rao RS, Sahoo S, Shashikala P, Kanungo R, Jayachandran S, et al. 2009. Phenotypic and genotypic assays for detecting the prevalence of metallo-b-lactamases in clinical isolates of Acinetobacter baumannii from a South Indian tertiary care hospital. J. Med. Microbiol. 58: 430-435.

22. Bassetti M, Righi E, Esposito S, Petrosillo N, Nicolini L. 2008. Drug treatment for multidrug-resistant Acinetobacter baumannii infections. Future Microbiol. 3: 649-660.

23. Bonomo RA, Szabo D. 2006. Mechanisms of multidrug resistance in Acinetobacter Species and Pseudomonas aeruginosa. Clin. Infect. Dis. 43: S49-S56.

24. Bonnin RA, Nordmann P, Poirel L. 2013. Screening and deciphering antibiotic resistance in Acinetobacter baumannii: A state of the art. Expert Rev. Anti. Infect. Ther. 11: 571-583.

25. Abdulzahra AT, Khalil MAF, Elkhatib WF. 2018. First report of colistin resistance among carbapenem-resistant Acinetobacter baumannii isolates recovered from hospitalized patients in Egypt. New Microbes New Infect. 26: 53-58.

26. Sadeghifard N, Ranjbar R, Zaeimi J, Alikhanid MY, Ghafouryana S, Raftarie M, et al. 2010. Antimicrobial susceptibility, plasmid profiles, and RAPD-PCR typing of Acinetobacter bacteria. Asian Biomed. 4: 901-911.

27. Shehta H, Abdalbagi S, Benmahmod B, Hassan R. 2018. Coproduction of $\mathrm{AmpC}$ and extended spectrum beta-lactamases in cephalosporin-resistant Acinetobacter baumannii in Egypt. World J. Microbiol. Biotechnol. 34: 189.

28. Azizi O, Shahcheraghi F, Salimizand H, Modaresi F. 2016. Molecular analysis and expression of bap gene in biofilm-forming multidrug-resistant Acinetobacter baumannii. reports. Biochem. Mol. Biol. 5: 62-72.

29. Petrova AP, Stanimirova ID, Ivanov IN, Petrov MM, MitevaKatrandzhieva TM, Grivnev Vl, et al. 2017. Carbapenemase production of clinical isolates Acinetobacter baumannii and Pseudomonas aeruginosa from a Bulgarian University Hospital. Folia Med. (Plovdiv) 59: 413-422.

30. Nwadike, Ugochukwu V, Kingsley C, Iche E. 2014. Multidrug resistant Acinetobacter infection and their antimicrobial susceptibility pattern in a Nigerian Tertiary Hospital ICU. J. Infect. Dis. 8: 14-18.

31. Eftekhar F, Torkanpoory NE. 2018. Contribution of contaminated environmental surfaces to the transmission of multidrug-resistant Acinetobacter baumannii in special care units of a hospital in Tehran, Iran. J. Med. Microbiol. Infect. Dis. 6: 37-42.
32. Lean $\mathrm{S}$, Suhaili Z, Ismail $\mathrm{S}$, Rahman NIA, Othman N, Abdullah FH, et al. 2014. Prevalence and genetic characterization of carbapenem- and polymyxin-resistant Acinetobacter baumannii isolated from a tertiary hospital in terengganu, Malaysia. ISRN Microbiol. 2014: 953417.

33. Fouad M, Attia AS, Tawakkol WM, Hashem AM. 2013. Emergence of carbapenem-resistant Acinetobacter baumannii harboring the OXA-23 carbapenemase in intensive care units of Egyptian hospitals. Int. J. Infect. Dis. 17: e1252-e1254.

34. Ertürk A, Çiçek AC, Gümü A, Cüre E, Ahmet Ş, Kurt A, et al. 2014. Molecular characterisation and control of Acinetobacter baumannii isolates resistant to multi-drugs emerging in inter-intensive care units. Ann. Clin. Microbiol. Antimicrob. 13: 36.

35. Pogue JM, Mann T, Barber KE, Kaye KS. 2013. Carbapenem-resistant Acinetobacter baumannii: Epidemiology, surveillance and management. Expert Rev. Anti. Infect. Ther. 11: 383-393.

36. Evans BA, Amyes SGB. 2014. OXA beta-Lactamases. Clin. Microbiol. Rev. 27: 241-263.

37. Al-Agamy MH, Khalaf NG, Tawfick MM, Shibl AM, El Kholy A. 2014. Molecular characterization of carbapenem-insensitive Acinetobacter baumannii in Egypt. Int. J. Infect. Dis. 22: 49-54.

38. Hamouda A, Evans BA, Towner KJ, Amyes SGB. 2010. Characterization of epidemiologically unrelated Acinetobacter baumannii isolates from four continents by use of multilocus sequence typing, pulsed-field gel electrophoresis, and sequence-based typing of bla OXA-51-like genes. J. Clin. Microbiol. 48: 2476-2483.

39. Touati M, Diene SM, Racherache A, Dekhil M, Djahoudi A, Rolain JM. 2012. Emergence of blaOXA-23 and blaOXA-58 carbapenemase-encoding genes in multidrug-resistant Acinetobacter baumannii isolates from University Hospital of Annaba, Algeria. Int. J. Antimicrob. Agents 40: 84-93.

40. Abbott I, Cerqueira GM, Bhuiyan S, Peleg AY. 2013. Carbapenem resistance in Acinetobacter baumannii: laboratory challenges, mechanistic insights and therapeutic strategies. Expert Rev. Anti. Infect. Ther. 11: 395-409.

41. Merino Má, Poza M, Roca I. 2014. Nosocomial outbreak of a multiresistant Acinetobacter baumannii expressing OXA-23 carbapenemase in Spain. Microb. Drug Resist. 20: 259-263.

42. Dettori M, Piana A, Deriu MG, Lo Curto P, Cossu A, Musumeci R, et al. 2014. Outbreak of multidrug-resistant Acinetobacter baumannii in an intensive care unit. New Microbiol. 37: 185-191.

43. Perez F, Endimiani A, Ray AJ, Decker BK, Wallace CJ, Hujer KM, et al. 2010. Carbapenem-resistant Acinetobacter baumannii and Klebsiella pneumoniae across a hospital system : impact of postacute care facilities on dissemination. J. Antimicrob. Chemother. 65: 1807-1818.

44. Farshadzadeh Z, Hashemi FB, Rahimi S, Pourakbari B. 2015. Wide distribution of carbapenem resistant Acinetobacter baumannii in burns patients in Iran. Front. Microbiol. 6: 1146.

45. Vali L, Dashti K, Opazo-capurro AF, Dashti AA, Al Obaid K, Evans BA. 2015. Diversity of multi-drug resistant Acinetobacter baumannii population in a major hospital in Kuwait. Front. Immunol. 6: 743. 
46. Lopes BS, Al-agamy MH, Ismail MA, Shibl AM, Al-Qahtani AA, AlAhdal MN, et al. 2015. The transferability of blaOXA-23 gene in multidrug-resistant Acinetobacter baumannii isolates from Saudi Arabia and Egypt. Int. J. Med. Microbiol. 305: 581-588.

47. Zowawi HM, Sartor AL, Sidjabat HE, Balkhy HH, Walsh TR, Al Johani SM, et al. 2015. Molecular epidemiology of carbapenemresistant Acinetobacter baumannii isolates in the gulf cooperation council states : Dominance of OXA-23-Type producers. J. Clin. Microbiol. 53: 896-903.

48. Ranjbar R, Zayeri S, Afshar D, Farshad S. 2019. Detection of OXA beta lactamases among clinical isolates of Acinetobacter baumannii isolated from Tehran hospitals, Iran. Open Microbiol. J. 13: 68-72.

49. Handal R, Qunibi L, Sahouri I, Juhari M, Dawodi R, Marzouqa $H$, et al. 2017. Characterization of carbapenem-resistant Acinetobacter baumannii strains isolated from hospitalized patients in palestine. Int. J. Microbiol. 2017: 8012104.

50. Chang Y, Luan G, Xu Y, Wang Y. 2015. Characterization of carbapenem-resistant Acinetobacter baumannii isolates in a Chinese teaching hospital. Front. Microbiol. 6: 690.

51. Bannah AMS El, Nawar NN, Hassan RMM, Salem STB. 2017. Molecular epidemiology of carbapenem-resistant Acinetobacter baumannii in a tertiary care hospital in Egypt : clonal spread of bla OXA-23. Microb. Drug Resist. 24: 269-277.

52. Al Atrouni A, Hamze M, Jisr T, Limarie C, Eveillard M, Joly-Guillou
M, et al. 2016. Wide spread of OXA-23-producing carbapenemresistant Acinetobacter baumannii belonging to clonal complex II in different hospitals in Lebanon. Int. J. Infect. Dis. 52: 29-36.

53. Pujol C, Joly S, Lockhart SR, Noel S, Tibayrenc M, Soll DR. 1997. Parity among the randomly amplified polymorphic DNA method, multilocus enzyme dlectrophoresis, and southern blot hybridization with the moderately repetitive DNA probe Ca3 for fingerprinting Candida albicans. J. Clin. Microbiol. 35: 2348-2358.

54. Li X, Xie Y, Wang M, Xia X, Wang M, Cao W, et al. 2016. Phenotypic and genomic diversity in Acinetobacter baumannii stains random isolated from 2008 to 2012 in a teaching hospital in Hunan, China. Int. J. Clin. Exp. Pathol. 9: 7030-7039.

55. Kanj SS, Tayyar R, Shehab M, El-Hafi B, Rasheed SS, Kissoyan KAB, et al. 2018. Increased bla OXA-23-like prevalence in Acinetobacter baumannii at a tertiary care center in Lebanon (2007-2013). J. Infect. Dev. Ctries 12: 228-234.

56. Novovic K, Mihajlovic S, Vasiljevic Z, Filipic B. 2015. Carbapenemresistant Acinetobacter baumannii from Serbia : Revision of CarO classification. PLoS One 10: e0122793.

57. Koeleman JGM, Stoof J, Biesmans DJ, Savelkoul PH, Vandenbroucke-Grauls CM. 1998. DNA Analysis, and amplified fragment length polymorphism fingerprinting for identification of acinetobacter gnomic species and typing of Acinetobacter baumannii. J. Clin. Microbiol. 36: 2522-2529. 